\title{
Xenotrasplante renal. El rechazo vascular agudo
}

\author{
González Martín $\mathrm{M}^{1}$, García Buitrón $\mathrm{J}^{2}$, Alonso Hernández $\mathrm{A}^{3}$, Centeno Cortés $\mathrm{A}^{4}$, López Peláez E $\mathrm{E}^{4}$, \\ Vázquez Martul E${ }^{5}$, Mosquera Reboredo ${ }^{5}$, Requejo Isidro I ${ }^{6}$, Máñez Mendiluce $\mathrm{R}^{7}$. \\ ${ }^{1}$ Servicio de Urología. ${ }^{2}$ Coordinación de Trasplantes. ${ }^{3}$ Servicio de Nefrología. ${ }^{4}$ Unidad de Cirugía Experimental. \\ ${ }^{5}$ Servicio de Anatomía Patológica. ${ }^{6}$ Servicio de Radiodiagnóstico. ${ }^{7}$ Director Programa Xenotrasplante. Hospital \\ Universitario Juan Canalejo-Fundación Barrié de la Maza. La Coruña. España.
}

Actas Urol Esp. 2008;32(1):152-159

\section{RESUMEN}

XENOTRASPLANTE RENAL. EL RECHAZO VASCULAR AGUDO

Introducción y objetivos: El trasplante de órganos es hoy una práctica habitual y de éxito, pero de aplicación limitada, debido a la insuficiencia de órganos. Anualmente miles de pacientes en lista de espera fallecen, esperando un órgano. En EEUU en el 2005 la lista de espera para trasplantes de órganos, riñón, corazón, hígado, pulmón, páncreas era de 94.419. El número de trasplantes realizados fue de 27.966 y el de fallecidos esperando un órgano 41.392. (1)

El xenotrasplante de órganos de cerdo es una de las esperanzas para aliviar la falta de órganos para el trasplante. La disponibilidad de cerdos con distintas modificaciones genéticas, creó grandes expectativas sobre una pronta utilización clínica de los mismos, sin embargo, aunque los estudios experimentales preclínicos con el riñón han alcanzado supervivencias prolongadas, estas son insuficientes para dar el paso a la fase clínica.

El rechazo hiperagudo $(\mathrm{RH})$ con destrucción del órgano de forma inmediata, habitual en el trasplante de órganos entre especies distintas filogenéticamente (trasplante discordante) puede en la actualidad ser evitado sin embargo, la aparición de un posterior rechazo humoral agudo (RHA) también llamado rechazo vascular agudo (RVA) o xenorechazo agudo retardado, da lugar al fracaso del xenotrasplante. La utilización de distintas pautas de inmunosupresión han conseguido retrasar de forma significativa este rechazo, pero no lo previenen de forma sistemática.

El xenotrasplante como opción terapéutica plantea importantes problemas científicos, éticos y sociales. En este artículo exponemos un resumen de nuestra experiencia en xenotrasplante renal y comentamos los problemas del RVA.

Material y método: Se han practicado 20 xenotrasplantes renales de cerdo transgénico hDAF (donante) a babuino (receptor). El peso de los cerdos osciló entre 11,400 y $75 \mathrm{~kg}$. y el de los babuinos entre 10 y 26,500 kg. El peso del xenoinjerto, riñón del cerdo, osciló entre 39 y $160 \mathrm{~g}$.

Resultados: La supervivencia media de los animales estuvo entre 7-9 días. El estudio histológico final de los injertos mostró cambios secundarios a necrosis tubular aguda mezclados con alteraciones propias de rechazo agudo. Tres injertos se perdieron por problemas técnicos mayores.

Conclusiones: Aunque hemos observado resultados prometedores, el xenotrasplante es una cuestión de gran dificultad, especialmente a largo plazo. Se precisa aún en la actualidad de mucha actividad investigadora en este campo.

Palabras clave: Xenotrasplante. Rechazo vascular agudo. Babuino, cerdo, riñon

\section{ABSTRACT}

RENAL XENOTRANSPLANT. ACUTE VASCULAR REJECTION

Introduction and objectives: Organ transplant is nowadays a usual and succesful practice, although with limited application due to the lack of organs. Yearly thousands of patients get access to the waiting list and finally will death while they are waiting for an organ. In USA, 2005 waiting list for kidneys, heart, liver lung and pancreas was around 94.419. Number of transplants performed was 27.966 and died patients while waiting for an organ, 41.392 (1). Pig xenotransplant is one of the possibilities to ameliorate the lack of organs for transplant. Arrangement of pigs with different genetic modifications generated great expectatives on the use of these organs in clinics. Although preclinical experimental studies with kidneys reached prolonged survivals, these are really insufficient to go on with the clinical appliance. Hyperacute rejection produces destruction of the organ immediately. This problem could be pharmacologically precluded in xenotransplant. However, acute rejection or vascular rejection usually produces the lost of the implant. New inmunosuppresive schedules delay significantly rejection, but not definitively.

Xenotransplant as a therapeutic option introduces important scientific problems, as well as ethical and social. This paper reports a summary of our experience in renal xenotransplant and the management of acute rejection.

Material and methods: Twenty xenotransplants from transgenic pig (hDAF) as donor to babuine as receptor. Average weight of the animals ranged 11.4-75 kgrs and babuines 10-26 kg. Xenograft average weight ranged 39-160 grs. Implant was performed to aorta and cava. Four inmunosupressive schedules were used.

Results: Average survival was 7-9 days. Final Histological findings are described. Changes observed were secondary to acute tubular necrosis mixed with changes due to acute rejection. Three grafts were lost due to technical major problems.

Conclusions: Although we have observed some promising results, xenotransplant is a very difficult problem to solve in the long-term. A lot of research is still needed-

Keywords: Acute vascular rejection. Xenotransplant. Babuine, pig, kidney. 
$\mathrm{E}^{1}$ 1 trasplante de órganos es hoy una práctica habitual y de éxito, pero de aplicación limitada, debido a la insuficiencia de órganos. Anualmente miles de pacientes en lista de espera fallecen, esperando un órgano. En EEUU en el 2005 la lista de espera para trasplantes de órganos, riñón, corazón, hígado, pulmón, páncreas era de 94.419. El número de trasplantes realizados fue de 27.966 y el de fallecidos esperando un órgano $41.392^{1}$.

El xenotrasplante de órganos de cerdo es una de las esperanzas para aliviar la falta de órganos para el trasplante. La disponibilidad de cerdos con distintas modificaciones genéticas, creó grandes expectativas sobre una pronta utilización clínica de los mismos, sin embargo, aunque los estudios experimentales preclínicos con el riñón han alcanzado supervivencias prolongadas, estas son insuficientes para dar el paso a la fase clinica.

El rechazo hiperagudo $(\mathrm{RH})$ con destrucción del órgano de forma inmediata, habitual en el trasplante de órganos entre especies distintas filogenéticamente (trasplante discordante) puede en la actualidad ser evitado sin embargo, la aparición de un posterior rechazo humoral agudo (RHA) también llamado rechazo vascular agudo (RVA) o xenorechazo agudo retardado, da lugar al fracaso del xenotrasplante. La utilización de distintas pautas de inmunosupresión han conseguido retrasar de forma significativa este rechazo, pero no lo previenen de forma sistemática.

El xenotrasplante como opción terapéutica plantea importantes problemas científicos, éticos y sociales. En este artículo exponemos un resumen de nuestra experiencia en xenotrasplante renal y comentamos los problemas del RVA.

\section{MATERIAL Y MÉTODO}

Donante: cerdo transgénico- Receptor: babuino.

Se han practicado 20 xenotrasplantes renales de cerdo transgénico hDAF (donante) a babuino (receptor). El peso de los cerdos osciló entre 11,400 y $75 \mathrm{~kg}$ y el de los babuinos entre $10 \mathrm{y}$ $26,500 \mathrm{~kg}$. El peso del xenoinjerto, riñón del cerdo, osciló entre 39 y 160 g.

\section{Técnica quirúrgica en el cerdo}

La extracción de los riñones se realiza a través de incisión media transperitoneal. Una vez liberados se extraen ambos riñones, seleccionando el que va a se trasplantado en base a la anatomía del pedículo vascular. El otro se utilizará para estudios anatomopatológicos básicos y comparativos. Se perfunde con Eurocollins y se mantiene en frío hasta ser trasplantado.

\section{Técnica quirúrgica en el babuino}

A través de incisión de laparotomía media transperitoneal se libera arteria aorta y vena cava. Posteriormente se realiza el trasplante anastomosando arteria renal a aorta y vena renal a cava (Fig. 1). El riñón queda ubicado en situación retroperitoneal y el uréter se implanta en vejiga según técnica Leadbetter-Politano. Al terminar el trasplante se realiza nefrectomía bilateral de los riñones propios y finalmente biopsia del riñón trasplantado.

\section{Control postoperatorio}

Se realizan estudios analíticos de Hematología y Bioquímica cada 24-48 h. y estudios inmunológicos periódicos (nivel de anticuerpos anti-galactosa $\alpha 1$-3 galactosa ( $\alpha \mathrm{Gal}$ ) IgM e IgG y anticuerpos hemolíticos porcinos (APHA), asî como ecografía protocolizada y en caso de complicaciones en la evolución.

\section{Inmunosupresión}

Todos los receptores recibieron GAS 914 sc, 1 $\mathrm{mg} / \mathrm{kl} / 72 \mathrm{~h}$ desde el día -17 al -5 y $1 \mathrm{mg} / \mathrm{kl} / 24$ $\mathrm{h}$ desde el día -4 al 0 y $1 \mathrm{mg} / \mathrm{kl} / 12 \mathrm{~h}$ posteriormente.

Se han utilizado cuatro protocolos de inmunosupresión:
A) Ciclofosfamida

Ciclosporina

Micofenolato mofetil

Corticoides

B) Ciclofosfamida

Ciclosporina

FTY 720

Corticoides
C) Basiliximab Ciclosporina FTY 720 Corticoides

D) Basiliximab

FTY 720

Everolimus

Corticoides 

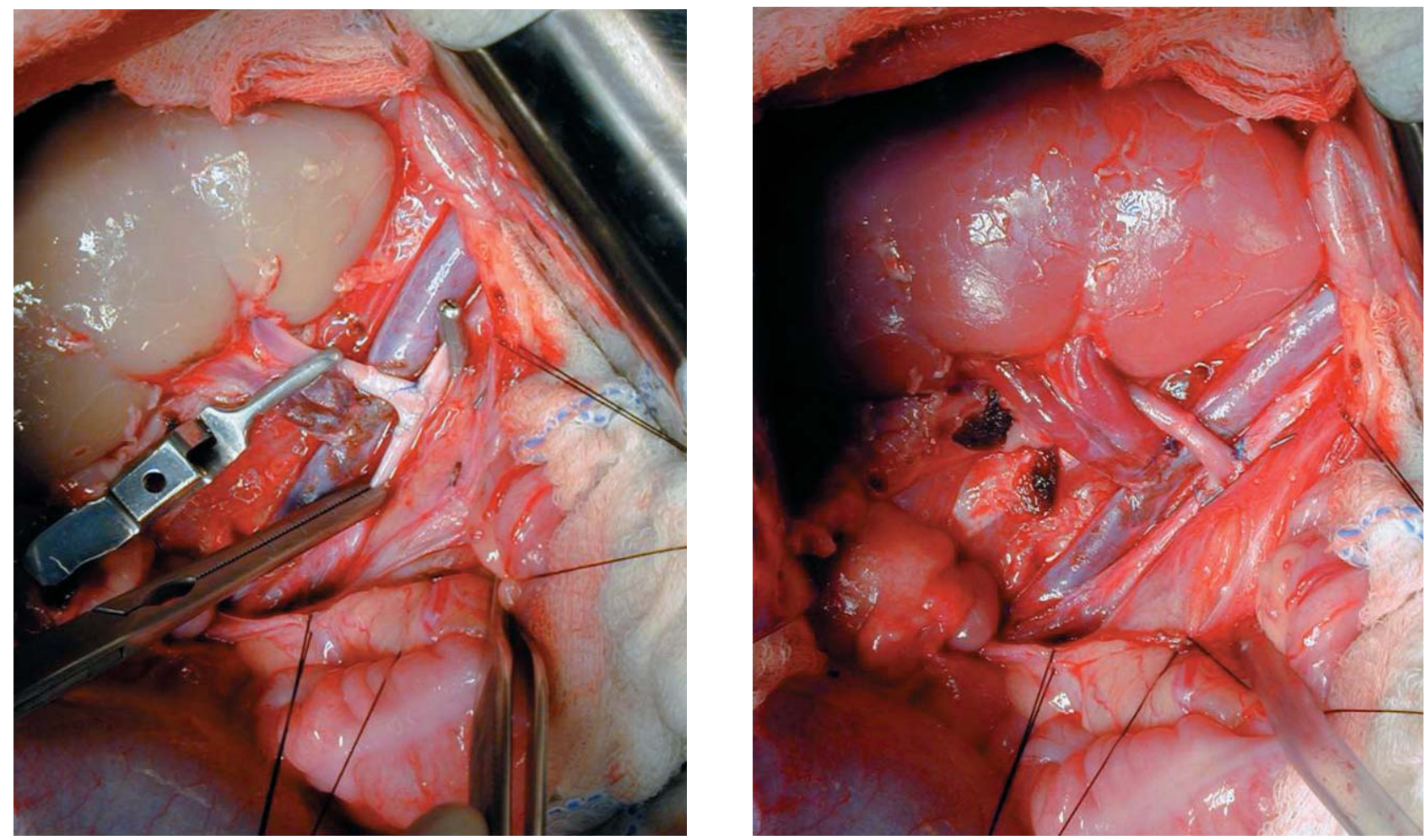

FIGURA 1. Xenotrasplante. A) Riñón trasplantado isquémico. B) Riñón trasplantado con circulación reestablecida.

\section{Resultados}

La mediana de la supervivencia de los xenoinjertos fue: 7 días (rango 1-31) con el protocolo de inmunosupresión A; 8 días (rango 4-28) con el B; 8 días (rango 3-13) con el C y 9 días (rango 1-20) con el D. En los casos de mejor evolución supervivencia más prolongada, los parámetros de la función renal (creatinina, urea) se normalizan en 3-4 dias (Figs. 2 y 3).

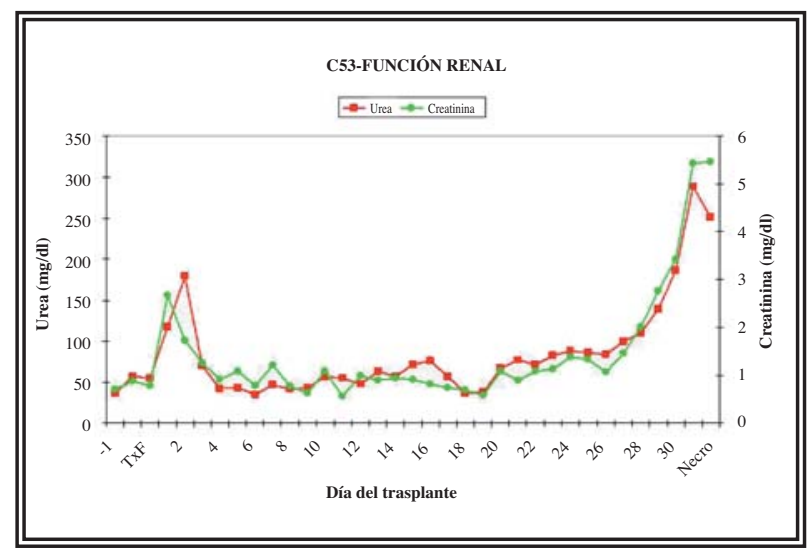

FIGURA 2. Gráfica de la evolución de la función renal, Creatinina y Urea, en supervivencia de 1 mes.

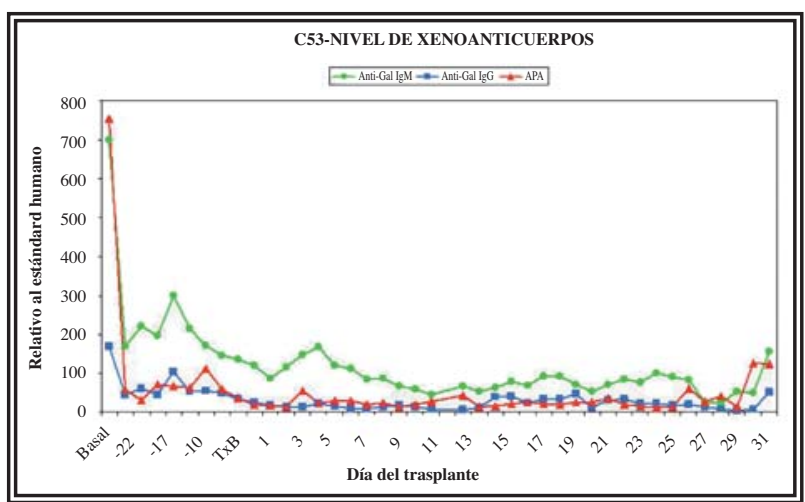

FIGURA 3. Gráfica de la evolución de los xenoanticuerpos en supervivencia de un mes.

La concentración de los anticuerpos antigalactosa $\alpha 1-3$ Galactosa ( $\alpha$-Gal) IgM, IgG y hemoliticos porcinos (AHPA) al tiempo del trasplante fueron (media $\pm \mathrm{SD}$ ) $134 \pm 70,85 \pm 78$ y $56 \pm 38$ repectivamente. No se observaron cambios al RHA en el nivel de los anticuerpos $\alpha$-Gal, IgM y IgG que fueron respectivamente $103 \pm 9$ y $38 \pm 49$. Sin embargo el RHA fue asociado con un notable aumento de APHA en 4 casos $(676 \pm 582)$ mientras en otros 6 casos no se observan cambios (34 \pm 12$)$ (Fig. 4). 


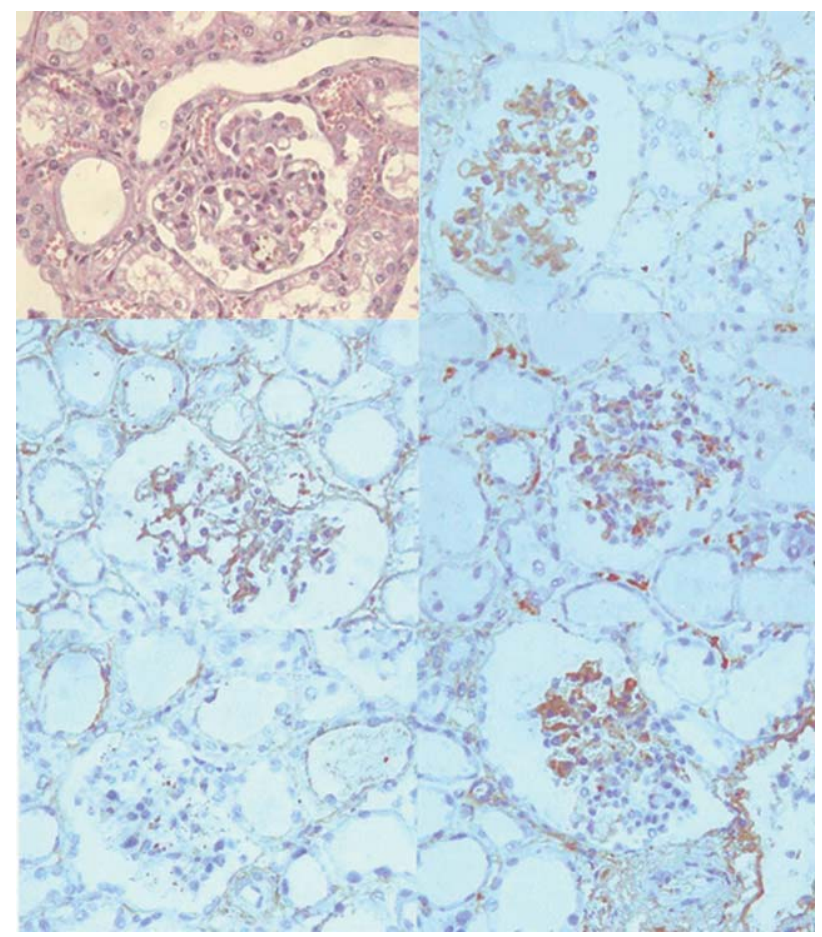

FIGURA 4. Rechazo humoral agudo.

Signos de necrosis tubular aguda con vacuolización citoplasmática del epitelio tubular. Depósitos lineales de immunocomplejos (IgG, IgM), fracciones de complemento (C4, C5b-9, fibrina) en vasos glomerulares y capilares del intersticio renal, con técnica de immunoperoxidasa.

La anemia normocítica, normocrómica y la hipoalguminemia fueron, en mayor o menor grado, habituales en todos los babuinos trasplantados a pesar del tratamiento con EPO.

En relación con los estudios histopatológicos, hemos dividido los 20 casos estudiados en 3 grupos. Grupo 1: En este grupo hemos incluido los 3 casos en los que el fracaso del injerto fue secundario a problemas técnicos (hemorragias y trombosis). Grupo 2: Está constituido por los 6 casos con fracaso del injerto en los primeros siete dias post-trasplante. En ambos grupos se descarta el rechazo vascular agudo (RVA) como responsable. Los cambios histológicos eran inespecíficos con diferentes grados de NTA y depósitos focales de IgM. Grupo 3: Todos los injertos incluidos en este grupo desarrollaron fracaso funcional del injerto entre los dias 8 y 31 post-trasplante. En todos los casos existía afectación a nivel glomerular consistente en lesiones de tipo microangiopático, caracterizado por intensa congestión capilar, ensanchamiento de membrana basal capilar glo- merular, presencia de trombos y/o ensanchamiento mesangial. Los túbulos mostraban signos de necrosis tubular aguda en distintos grados, con descamación, cilindros hemáticos y/o granulosos. En algunos casos destacaba la presencia de hemorragia intersticial, necrosis y congestión capilar peritubular. El estudio inmunohistoquímico mostró, en todos los casos, depósitos de IgM, C3, C4 y C5b9 localizado preferentemente en los capilares peritubulares y/o glomerulares. Los hallazgos histológicos e inmunohistoquimicos son compatibles con RVA.

Dos xenoinjertos fracasaron en los dias 28 y 31 del trasplante por causas no inmunológicas (CMV y obstrucción ureteral respectivamente).

\section{COMENTARIOS}

Los primates humanos y no humanos pertenecen al mismo orden zoológico por lo cual los segundos podrian ser desde el punto de vista genético los donantes ideales. En la década de los 60 se realizaron, con éxito prolongado, este tipo de trasplantes renales: trasplantes concordantes. El chimpacé, gorila, y orangután son los más cercanos y compatibles, en tamaño y tipos sanguíneos pero no son aceptados como fuente de órganos. Su proximidad a la especie humana y dificultades de reproducción en cautividad hace que sea socialmente no viable el proyecto (Fig. 5).

El babuino tiene anatomía y fisiología similares a los humanos. Los diferentes grupos sanguineos y sobre todo el miedo a la transmisión de enfermedades infecciosas, virus, retrovirus, toxoplasma, etc. También lo hacen inviable.

El cerdo convive con nosotros, consumimos habitualmente sus productos, sin ningún rechazo social y ético, se reproduce rápida y fácilmente. Por pertenecer a especie filogenéticamente

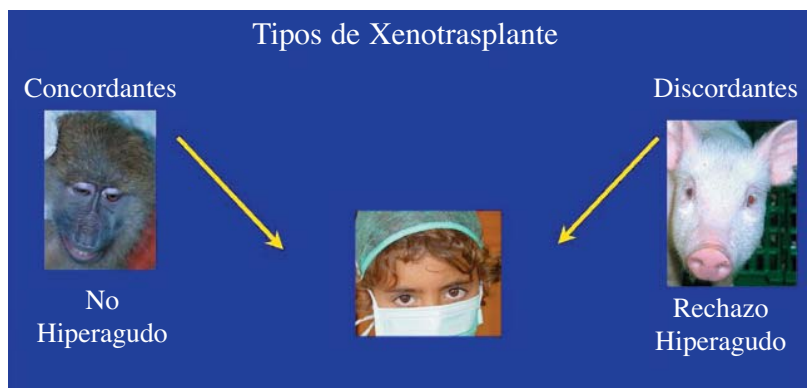

FIGURA 5. Tipos de xenotrasplante: concordante y discordante. 
distinta, los órganos de cerdo no modificado, trasplantados en primate no humano (xenotrasplante discordante) son rápidamente destruidos por el RH. Esto tiene lugar porque los xenoanticuerpos naturales o preformados se depositan en el endotelio del injerto después de la revascularización del órgano, activando el complemento y la coagulación, y dando como resultado un daño irreversible en pocos minutos del endotelio, con trombosis y oclusión vascular (Fig. 6).

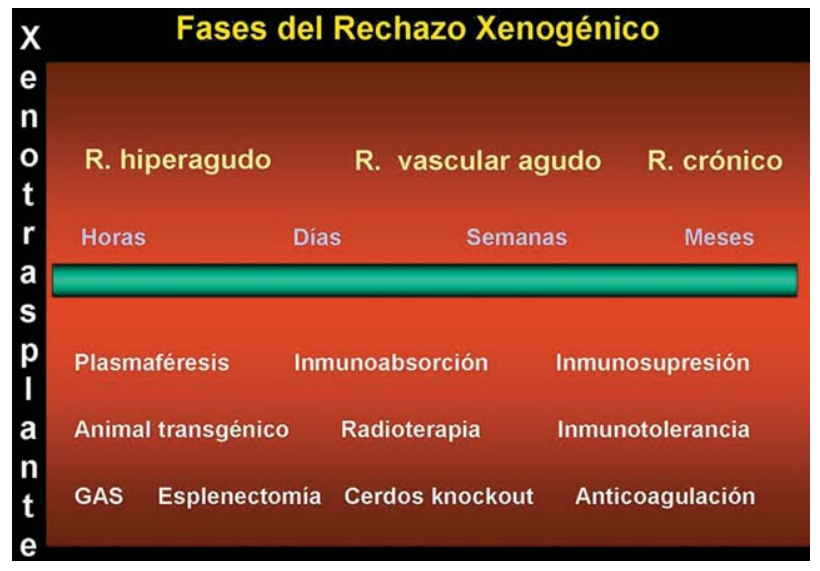

FIGURA 6. Fases del rechazo en el xenotrasplante.

Los tratamientos inmunosupresores, eficaces para inhibir la producción de anticuerpos inducidos, no lo son para neutralizar los anticuerpos naturales, de ahí que la primera barrera que debía vencer el xenotrasplante de órganos de cerdo era el rechazo hiperagudo, semejante al rechazo que tiene lugar cuando se realiza un trasplante entre grupos sanguíneos incompatibles.

Los anticuerpos humanos capaces de fijar el complemento y producir el rechazo hiperagudo son esencialmente IgM y en menor proporción IgG e identifican una sola estructura: el disacárido, galactosa, $\alpha 1-3$, galactosa $(\alpha \mathrm{Gal})^{2}$.

Las técnicas para neutralizar o eliminar los xenoanticuerpos, como plasmaféresis o inmunoadsorción, sólo lo hacen de forma transitoria, reapareciendo en un corto espacio de tiempo tras la supresión del procedimiento ${ }^{3}$.

Una forma más específica para evitar la activación del complemento ha sido la producción de cerdos transgénicos, que expresan en la membrana de sus células las proteínas reguladores del complemento humano, DAF, CD59, MCP o diversas combinaciones de las mismas ${ }^{4,5}$. Con los órganos de estos cerdos se evita el rechazo hiperagudo en la mayoria de las ocasiones persistiendo en otras ocasiones por causas no aclaradas ${ }^{6}$.

La prevención habitual del RH representa un avance fundamental para poder trasplantar algún día órgano de cerdo en humanos, sin embargo no ha sido la solución definitiva como inicialmente se pensó. Cuando esta reacción no tiene lugar aparece posteriormente un RVA o xenorechazo agudo retardado, que es la causa más frecuente del fracaso de los cerdos transgénicos para las proteínas reguladoras del complemento humano.

Lesiones sugestivas de RVA consistentes en microangiopatía glomerular, intensa congestión capilar y presencia de trombos estuvieron presentes en el Grupo 3. La confirmación del diagnóstico de RVA se realizó por la existencia de depósitos variable de IgM, IgG, C3, C4, C5b-9 y fibrina, que indican activación del complemento y coagulación como consecuencia del depósito de anticuerpos en el endotelio del órgano trasplantado.

Los cambios inespecíficos, que observamos en el Grupo 2 de nuestros casos, pueden ser debidos a distintos factores. Por un lado podría corresponder a un estadio inicial de un RVA, ya que, en los primeros días postrasplantes los cambios histológicos son mínimos y/o inexistentes. Además algunos autores no consideran necesarios los depósitos de complemento para establecer el diagnóstico de rechazo humoral ${ }^{7}$. Sin embargo, lo más posible es que nos encontremos ante factores no inmunológicos (medicamentos, hipotensión, isquemia) que de forma individual o al combinarse varios de ellos, dan lugar a una NTA, que sería potencialmente reversible si pudiéramos realizar diálisis temporalmente.

Colvin et $a .^{8}$ describen tres grados de RVA según la intensidad de los cambios histológicos. Asimismo, establecen la cronología histológica, indicando que en la primera semana postranplante las alteraciones histológicas son mínimas con depósitos focales de IgM, IgC y C3 y que después de los primeros siete días es cuando empiezan a observarse signos histológicos sugestivos de rechazo vascular agudo. Nuestros resultados 
confirman esta cronología y demuestran que los mismos pueden tener lugar en el xenoinjerto, sin que existan cambios en los niveles de anticuerpos detectados en la sangre en más de la mitad de los casos. Esto sugiere que estos anticuerpos se depositan en el xenoinjerto renal, y sólo tras saturar la diana de los mismos en el órgano son detectados en la circulación. En consecuencia los tratamientos deben dirigirse a la prevención del depósito de anticuerpos, ya que una vez estos son detectados en la sangre, es muy posible que exista ya un daño significativo del xenoinjerto.

La elevada frecuencia del RVA como causa del fracaso de los órganos de cerdo transgénico, para las proteínas humanas reguladoras del complemento, en primates no humano, ha convertido la prevención/tratamiento del mismo en el objetivo más importante del xenotrasplante. En nuestro estudio se han utilizado cuatro protocolos de inmunosupresión, que no han mostrado diferencias significativas en la supervivencia de los xenoinjertos, incorporando todos la utilización de GAS 914. Esta molécula consiste en una polilisina que lleva ancladas moléculas de $\alpha$-Gal, lo que permite neutralizar de forma continua y especifica, antes y después del trasplante los anticuerpos $\alpha-\mathrm{Gal}^{9}$. Sin embargo, su utilización con la idea de prevenir el RVA no ha dado el resultado esperado.

La CyP fue incluida desde un principio en los protocolos de inmunosupresión en el xenotrasplante de órganos de cerdo transgénico en primates no humanos, ya que es el medicamento más potente conocido hasta el momento para inhibir la producción de anticuerpos. Nuestros resultados confirman esta eficacia, ya que el grupo A, que combina CyP en inducción, junto con CyA, MNa y corticoesteroides para mantenimiento, es el que demuestra una menor incidencia de RVA. Sin embargo, también demuestra los importantes efectos secundarios que comporta este protocolo, ya que la mayoría de xenoinjertos fracasaron por causas no inmunológicas.

Estos resultados son similares a los obtenidos por Cozzi et al. ${ }^{10}$ en los que la sustitución de la administración continúa de CyP por Micofenolato Mofetil (mismo principio activo), y una inducción perioperatoria de 4 dosis CyP, alcanza una máxima supervivencia de 51 días, con media de 21 , aunque el grado de severidad de las lesiones de RVA fue aparentemente menor. Este régimen terapéutico, inducción con CyP y mantenimiento de la inmunosupresión con CyA y Micofenolato, ha permitido alcanzar 3 meses de supervivencia. Sin embargo, la causa del fracaso renal fue un RVA, lo que indica que puede aparecer incluso tras periodos prolongados de supervivencia del xenoinjerto ${ }^{11}$.

La utilización de agentes monoclonales frente al receptor de interleuquina 2 (IL-2) como el Basiliximab, el monoclonal anti CD-20, Rituximab, como sustituto de la CyD, tampoco han mejorado los resultados, logrando supervivencia máxima de 26 días de los xenoinjertos renales en babuino ${ }^{12}$, al igual que ocurrió en nuestro estudio. De forma similar, los anticuerpos policlonales tampoco han permitido un avance significativo en la prevención del RVA. Ghanekar et al. ${ }^{13}$ utilizaron cerdos transgénicos, GAS 914, CyP, RAD, suero antitimocítico (RATS) y RAD o RATS solamente. La supervivencia no varió estadísticamente (entre 3 y 4 semanas) y los animales fallecieron por fracaso renal tras rechazo humoral o complicaciones en relación con la inmunosupresión. A pesar de los resultados, los autores sugieren que la utilización de RATS mejora el RVA.

Otras técnicas como la esplenectomía, que ha sido empleada con éxito en trasplante renal humano $\mathrm{ABO}$ incompatible ${ }^{14}$, también se han empleado en el xenotrasplante de cerdo-hDAFbabuino junto con tratamiento con CyP, CyA y esteroides logrando larga supervivencia ${ }^{15}$. En 4 de 9 animales más de 50 días, unos de ellos 78 . De todas formas el estudio anatomopatológico mostró lesiones de RVA grado III en todos los riñones porcinos, excepto en el de mayor duración, que fue grado I.

Estrategia diferente de la inmunosupresión para superar la barrera del RVA, ha sido la inducción de tolerancia mediante trasplante de médula ósea ${ }^{16}$, trasplante de bazo ${ }^{17}$. Se han publicado interesantes experiencias trasplantando el compuesto timo-riñón. En un primer tiempo se implanta tejido tímico bajo la cápsula renal de los cerdos y posteriormente se trasplanta el compuesto timo-riñón en babuinos. En el régimen de inmunosupresión se incluye timectomía o 
irradiación tímica en el receptor logrando prolongadas supervivencias del injerto merced a la inducción de rápida tolerancia ${ }^{18-20}$.

Un impulso significativo en la búsqueda de solución del RVA ha sido la posibilidad de clonar cerdos carentes de la enzima Galactosiltransferasa (cerdos Knockout) mediante la eliminación del gen que la codifica. Esta enzima es necesaria para la generación de los epítopos $\alpha$-Gal hacia los cuales van dirigidos la mayoría de los anticuerpos humanos naturales. Con ello se pretende evitar no sólo el rechazo hiperagudo sino también el RVA.

Yamada et al. ${ }^{21}$ comunican resultados iniciales del trasplante del compuesto timo-riñón usando cerdos $\alpha 1-3$ Galactosiltransferasa knockout, como donantes y babuinos receptores, logrando las supervivencias más prolongadas hasta la fecha con normal función a los 80 días. Los injertos aparecen normales a la inspección y muestran pequeños focos microscópicos de microangiopatía trombótica. En estudios realizados no fueron detectados anticuerpos xenoreactivos $\alpha$-Gal específicos y no $\alpha$-Gal específicos y los riñones no presentaron signos de rechazo. En dos animales trasplantados al suprimir la inmunosupresión se produjo rápido rechazo.

Chen et al. ${ }^{22}$ en experiencia con el mismo tipo de cerdos transgénicos y régimen de inmunosupresión distinto (Glubulina antitimocítica, Tacrólimus, Micofenolato y esteroides) no obtuvo los mismos resultados. Se produjo el rechazo vascular agudo en dos semanas y aunque los anticuerpos anti $\alpha$-Gal permanecieron ausentes, si hubo incremento de los anti-no- $\alpha-G a l$. Se deduce que la intensidad y el régimen inmunosupresor juega también importante papel.

La microangiopatía trombótica es el hecho histológico predominante en el rechazo de los órganos sólidos del xenotrasplante. Cada vez se da más importancia a los trastornos de la tromboregulación. El rechazo del xenoinjerto se asocia a trombocitopenia y trastornos de los factores de coagulación que terminan en la coagulación intravascular diseminada y asociada a la activación de las células endoteliales, finaliza en la microangiopatía trombótica. Esto ocurre a pesar de la inhibición del completo y bajo nivel de anticuerpos.
La anticoagulación sistémica del receptor en modelos cerdos-primate han producido resultados mixtos. El tratamiento con antitrombina recombinante humana mejora y retarda el desarrollo de la coagulopatía en experiencias comunicadas por Cowan $^{23}$. También se han utilizado antiagregantes plaquetarios (Ajoene y Dipiridamol) ${ }^{24}$.

Teniendo en cuenta los posibles perjuicios, por complicaciones de sangrado, la forma más lógica y segura de inhibir la trombosis de los xenotrasplantes, es la modificación genética del donante para sobreexpresar las moléculas antitrombóticas en el endotelio. Este enfoque ha tenido éxito en distintos modelos de pequeños animales (roedores) y sugiere que la sobreexpresión de anticoagulantes en el endotelio del xenoinjerto inhibiría la trombosis intravascular moderando la respuesta humoral, incluso el rechazo cróni$\mathrm{co}^{25}$. La extrapolación de estos estudios al modelo cerdo primate son esperados con impaciencia.

Otra forma actual de incidir sobre el problema de la coagulación, es la utilización de las estatinas. Se ha comprobado que a parte de su efecto para disminuir los niveles de colesterol, tienen efectos antinflamatorios, anticoagulantes e inmunomoduladores. Son considerados como las "nuevas aspirinas". Se ha documentado la inhibición de la formación de trombina in vitro y en pacientes, la regulación de la expresión y actividad de la trombomodulina en las células endoteliales así como la protección de las células endoteliales contra la actividad del complento. En resumen las estatinas pueden modificar la respuesta inmune en el xenotrasplante porcino ${ }^{26}$.

Finalmente, se están dando pasos muy importantes para derribar la principal barrera que impide el xenotrasplante en clínica humana, el RVA. Otros obstáculos como la zoonosis, transmisión de infecciones, problemas de compatibilidad fisiológicas, éticos, sociales, también se están superando.

La experimentación clínica no permite en la actualidad iniciar el xenotrasplante como terapia definitiva. Tenemos la esperanza de que en el futuro será una realidad, como piensa Starzl 27 "La historia nos dice que los procedimientos que fueron inconcebibles ayer y dificilmente alcanzables hoy, a menudo se convierten en la rutina de mañana. Hoy el xenotrasplante es dificilmente alcanzable. Estoy convencido de que el xenotrasplante mañana se convertirá en rutina". 


\section{REFERENCIAS}

1. Newsletter. Transplant. ONT. Vol 11, $n^{\circ}$ 1, 2006.

2. Galili U, Macher BA, Buehler J, Shohet SB. Human natural anti-alpha-galactosyl IgG. II. The specific recognition of alpha (1-3)-linked galactose residues. J Exp Med. 1985; 162(2):573-582.

3. Taniguchi S, Neethling FA, Korchagina EY, Bovin N, Ye Y, Kobayashi $\mathrm{T}$, et al. In vivo immunoadsorption of antipig antibodies in baboons using a specific Gal(alpha)1-3Gal column. Transplantation. 1996;62(10):1379-1384.

4. Fodor WL, Williams BL, Matis LA, Madri JA, Rollins SA, Knight JW, et al. Expression of a functional human complement inhibitor in a transgenic pig as a model for the prevention of xenogeneic hyperacute organ rejection. Proc Natl Acad Sci USA. 1994;91(23):11153-11157.

5. Cozzi E, White DJ. The generation of transgenic as potential organ donors for humans. Nat Med. 1995;1(9):964966.

6. F.N. Bhatti, A. Zaidi, M. Schomoeckel, E. Cozzi G. Chavez, J. Wallwork, D.J. White. Prolonged survival of hDAF transgenic pig kidneys in primates. Transplantation. 1998; 65: 1584-1590.

7. Bühler L, Yamada K, Kitamura H, Alwayn IP, Basker M, Appel JZ 3rd, et al. Pig kidney transplantation in Baboons: Anti-Gal x 1-3 Gal IgM in associated with acute humoral xenograft rejection and disseminate intravascular coagulation. Transplantation. 2001;72(11):1743-1752.

8. Shimizu A, Meehan SM, Kozlowski T, Sablinski T, Ierino FL, Cooper DK, et al. Acute humoral xenograft rejection: destruction of the microvascular capillary endothelium in pig-to-non humam primate renal grafts. Lab Invest. 2000; 80(6):815-830.

9. R. Máñez, A. Centeno, E. López-Pelaez, C. Ruiz de Valbuena, A. Juffe, B. Holmes, R. Duthaler, A. Katopodis. GAS 914, a polylysine containing $\alpha \mathrm{Gal}$, prevents acute humoral rejection in hDAF pig to primate heterotopic heart xenotransplantation. Xenotransplantation. 2001;8(suppl 1):4.

10. Cozzi E, Vial C, Ostlie D, Farah B, Chavez G, Smith KG, et al. Maintenance triple immunosuppression with Cyclosporin mycophenolate sodium and steroids allows prolonged survival of primate recipients. Xenotrasplantation. 2003;10(4):300-310.

11. A. Dedja, P. Rigotti, N. Baldan, C. Cadrobbi, C. Vananzi, F. Calabrese, I. Iacopetti, R. Busetto, E. Cozzi, E. Ancona. Long-term survival on non-splenectomized Cynomologus monkeys receiving hDAF prorcine renal xenotgrafts and a maintenance immunosuppression with cyclosporine A, mycophenolate sodium and steroids. Libro Abstracs VI Congress Intern Xenotransplants. Assoc. Chicago IL. USA 2001; n409.

12. Y. Becker, D. Hullett, A. Friedi, S.O. Herrin, A. Usborne, Y. Yracheta, J. Aschenbrenner, H. Sollinger. Basiliximab and Rituximab increase survival in pig-to-baboon kidney xenotransplantation. Libro Abstracs VI Congress Intern Xenotransplants. Assoc. Chicago IL. USA 2001; $n^{\circ} 165$.

13. Ghanekar A, Lajoie G, Luo Y, Yang H, Choi J, Garcia B, et al. Improvement in rejection of human decay accelerating factor transgenic pig-to primate renal xenografts with administration of rabbit antithymocyte serum. Xenotransplantation. 2002;74(1):28-35.

14. G.P. Alexandre, J.P. Squiffet, D. Bruyere. Splenectomy as a prerequisite for successful human ABO-imcompatible renal transplantation. Transplant Proc. 1985;17:138.
15. Cozzi E, Bhatti F, Schmoeckel M, Chavez G, Smith KG, Zaidi A, et al. Long-term survival of nonhuman primates receiving life-supporting transgenic porcine kidney xenografts. Xenotransplantation. 2000;70(1):15-21.

16. M. Abe, J. Qi, M. Sykes, Y.G. Yang. Tolerance induction across a highly disparte xenogeneic barrier by bone marrow transplantation. Libro Abstracs VI Congress Intern Xenotransplants. Assoc. Chicago IL. USA 2001; ${ }^{\circ} 145$.

17. H. Zhang, Y Li, K. Wang, Y Ma. The status of chimeric cells in a guman to pig spleen trasnplantation model. Libro Abstracs VI Congress Intern Xenotransplants. Assoc. Chicago IL. USA 2001; n³22.

18. Barth RN, Yamamoto S, LaMattina JC, Kumagai N, Kitamura H, Vagefi PA, et al. Xenogeneic thymokidney and thymic tissue transplantation in a pig-to-baboon model: I. Evidence for pig-specific T-cell unresponsiveness. Transplantation. 2003;75(10):1615-1624.

19. Yamada K, Shimizu A, Ierino FL, Gargollo P, Barth R, Colvin RB, et al. Allogenic thymo-kiney transplants induce stable tolerance in miniature swine. Transplantation proceed. 1999;31(1-2):1199-1200.

20. Yamada K, Shimizu A, Utsugi R, Ierino FL, Gargollo P, Haller GW, et al. Thymic transplantation in miniature swine. II. Induction of tolerance by transplantation of composite thymokidneys to thymectomized recipients. Journal Immunol. 2000;164(6) 3079-3086.

21. Yamada K, Yazawa K, Shimizu A, Iwanaga T, Hisashi Y, Nuhn M, et al. Marked prolongation of porcine renal xenograft survival in baboons through the use of alpha1,3galactosyltransferase gene-knockout donors and the cotransplantation of vascularized thymic tissue. Nat Med. 2005; 11(1):32-34.

22. Chen G, Qian H, Starzl T, Sun H, Garcia B, Wang X, et al. Acute rejection is associated with antibodies to non-Gal antigens in baboons using Gal-knockout pig kidneys. Nat Med. 2005;11(12):1295-1298.

23. P. J. Cowan. Coagulation and the xenograft endothelium. Xenotransplantation. 2007,14:7-12.

24. K. Teranishi, S. Robson, E. Romano, D. Cooper, R. Apitx. Suppresion of baboon platelet agregation in vitro and in vivo by the garlic derivate, ajoene. Libro Abstracs VI Congress Intern Xenotransplants. Assoc. Chicago IL. USA 2001; n³00.

25. Chen D, Weber M, McVey JH, Kemball-Cook G, Tuddenham EG, Lechler RI, et al. Complete inhibition of acute humoral rejection using regulated expression of membrane-tethered anticoagulants on xenograft endothelium. Am J Transplant. 2004;4(12)1958-1963.

26. Ezzelarab M, Cooper DK. The potencial of statins in xenotransplantation. Comentary. Xenotransplantation. 2007; 14(2):100-103.

27. Groth CG. Progress in xenotransplantation: a personal view. Xenotransplantation. 2006;13(3):179-181.

Correspondencia autor: Dr. M. González Martín

Servicio de Urología.

Hospital Universitario Juan Canalejo

Xubias de Arriba, 84 - 15006 A Coruña

Tel.: 981178000

E-mail autor: urologia@canalejo.org

Información artículo: Original 